\title{
Psammaplin A is a natural prodrug that inhibits class I histone deacetylase
}

\author{
Dong Hoon $\mathrm{Kim}^{1}$, Jongheon $\mathrm{Shin}^{2}$ \\ and Ho Jeong Kwon ${ }^{1,3}$ \\ ${ }^{1}$ Department of Biotechnology \\ College of Engineering, Yonsei University \\ Seoul 120-749, Korea \\ ${ }^{2}$ Natural Products Research Institute \\ College of Pharmacy, Seoul National University \\ Seoul 110-460, Korea \\ ${ }^{3}$ Corresponding author: Tel, 82-2-2123-5883; Fax, 82-2-362-7265; \\ E-mail, kwonhj@yonsei.ac.kr
}

\section{Accepted 6 December 2006}

Abbreviations: BAECs, bovine aortic endothelial cells; BSO, butionine sulfoximine; HAT, histone acetylatransferase; HDAC, histone deacetylase; Psam A, psammaplin A; Psams, psammaplins; SAHA, suberoylanilide hydroxamic acid; TSA, trichostatin A

\begin{abstract}
Histone deacetylase (HDAC) has been highlighted as one of key players in tumorigenesis and angiogenesis. Recently, several derivatives of psam maplin (Psams) from a marine sponge have been known to inhibit the HDAC activity, but the molecular mechanism for the inhibition has not fully understood. Here, we explored the mode of action of Psams for the inhibition of HDAC activity in the molecular and cellular level. Among the derivatives, psammaplin A (Psam A) showed the potent inhibitory activity in enzyme assay and anti-proliferation assay with $\mathrm{IC}_{50}$ value of 0.003 and $1 \mu \mathrm{M}$, respectively. Psam A selectively induced hyperacetylation of histones in the cells, resulting in the upregulation of gelsolin, a well-known HDAC target gene, in a transcriptional level. In addition, reduced Psam A showed a stronger inhibitory activity than that of non-reduced one. Notably, glutathione-depleted cells were not sensitive to Psam A, implying that cellular reduction of the compound is responsible for the HDAC inhibition of Psam A after uptake into the cells. Together, these data demonstrate that Psam A could exhibit its activity under the reduced condition in the cells and be a new natural prodrug targeting HDAC.
\end{abstract}

Keywords: antineoplastic agents; histone deacetylases; prodrugs; psammaplin A

\section{Introduction}

Reversible acetylation of core histones is controlled by two families of enzymes, histone acetylases (HATs) and histone deacetylases (HDACs), respectively (Davie, 1998). Notably, perturbation of the balance between HAT and HDAC activities in normal cells and aberrant recruitment of HDACs by oncogenic proteins are implicated in several malignant diseases including cancer (Marks et al., 1978; Dhordain et al., 1998; Kim et al., 2001; 2005; Pandolfi, 2001).

HDAC is a hydrolase that has a zinc-binding site in tubular catalytic domain. All eleven human HDACs have deacetylase activity that is inhibited by small molecule such as a trichostatin A (TSA). Hyperacetylation of histones resulted from the inhibition of HDAC by specific inhibitors is physiologically linked to several cellular phenotypes such as cell-cycle arrest, cell-differenciation and cell death (Hoshikawa et al., 1994; Van Lint et al., 1996; Saito et al., 1999; Kim et al., 2003). Recently, inhibition of HDAC has been proposed for the treatment of cancer as well as neurodegenerative disorders associated with mutations in polyglutamine-encoding tract (Hockly et al., 2003). Accordingly, the inhibition of HDAC is a rapidly growing and very promising area for the development of anticancer drug (Vanhaecke et al., 2004). To date, several small molecules from natural sources and from chemical libraries have been developed as HDAC inhibitors with an aim for developing new anticancer agents (Piekarz et al., 2001; Kelly et al., 2003). Interestingly, FK228, one of natural HDAC inhibitors, exhibited a unique mode of action leading to the compound to be the first prodrug targeting HDAC (Furumai et al., 2002). The reducing agent such as glutathione mediated reduction of a disulfide bond in the FK228 converts the compound to be active leading to the coordination of sulfhydryl group to the zinc metal ion located at the HDAC catalytic pocket. Indeed, sulfhydryl group of FK228 and glutathione conjugates in blood were detected recently (Xiao et al., 2003). Consequently, small molecules having a similar activity with FK228 are valuable to be developed as they can decrease non-specific binding of the compound to cellular proteins that may contribute some side-effects or cytotoxicity of the compound. Thereafter, several HDAC inhibitors have been developed as HDAC prodrugs due to their clinical benefits (Batova et al., 2002; Nishino et al., 2003; Yurek-George et al., 
2004).

Psammaplin A (Psam A) isolated from a marine sponge was originally reported as an inhibitor of mycothiol-S-conjugate amidase and topoisomerase II (Kim et al., 1999; Nicholas et al., 2003) and the compound, more recently, showed anticancer activity against several cancer cell lines and A549 lung xenograph mouse model (Park et al., 2003; Pina et al., 2003). However, little is known about its mode of action to suppress carcinogenic properties of the cells. In our previous study, we found that Psam A suppresses angiogenesis in vitro through the inhibition of aminopeptidase N (APN), a zinc dependent metalloproteinase that plays a crucial role in metastatic tumor cell invasion (Shim et al., 2004). This finding opened a possibility, in part, to explain the antitumor activity of Psam $A$, although it required micromolar range of concentration to inhibit APN in vitro. Another plausible mechanism of Psam A for its anti-cancer activity was proposed by Crews group (Pina et al., 2003). They showed that psammaplins inhibited both activities of HDAC and DNA methyltransferase (DNMT) at the nanomolar concentraton in vitro, yet there was no detailed study on their HDAC inhibitory activity and mechanism in the cells.

In this study, we investigated the inhibitory activity of several Psam derivatives against HDAC in the cells and found that Psams, especially Psam A, can be reduced by a reducing agent and reduction of the compound is responsible for the release of a zinc-binding thiol group for its biological activity. This result provides a new insight how Psam $A$ inhibits the HDAC activity in the cells, and demonstrates that Psam A could be a new natural prodrug targeting HDAC.

\section{Materials and Methods}

\section{Chemicals}

Psam $A$ and its analogues were isolated from a marine sponge as described previously (Jung et al., 1995). Suberoylanilide hydroxamic acid (SAHA) was synthesized in our laboratory as described previously (Richon et al., 1996), and FK228 was kindly provided by Dr. Nakajima at Astellas Co., Japan. All stock concentrations were made in methanol and stored at $-20^{\circ} \mathrm{C}$. Butionine sulfoximine (BSO) and dithiothreitol (DTT) were purchased from Sigma (Sigma, St. Louis, MO). Protein A agarose beads was obtained from Upstate (Upstate biotechnology, Lake Placid, NY).

\section{Cell culture and proliferation assay}

Human cervical carcinoma cells (HeLa) were main- tained at $37^{\circ} \mathrm{C}$ under a humidified atmosphere of $5 \%$ $\mathrm{CO}_{2}$ in DMEM (Gibco, Grand Island, NY) supplemented with $10 \%(\mathrm{v} / \mathrm{v})$ heat-inactivated fetal bovine serum (FBS, Gibco), and 1\% antibiotics (Gibco) (Hur et al., 2005). The cells were plated on 96 well-plates, and incubated under a condition described above. After $24 \mathrm{~h}$, the cells were treated with various compounds for 3 days. Then, proliferation of the cells was measured using MTT assay, and morphology of the cells was observed using optical microscopy at a $\times 100$ magnification (Olympus Optical Inc., Melville, NY).

\section{In vitro enzyme assay}

HDAC enzymatic assay was performed with HDAC Fluorescent Activity Assay kit (Biomol, Plymouth Meeting, PA) according to the manufacturer's instruction. Briefly, nuclear fraction obtained from the cultured cells was lysed with $0.5 \%$ Triton $\mathrm{X}-100$ in phosphate buffer ( $\mathrm{pH}$ 8.0) and used as an enzyme source of HDAC. Using $10 \mu \mathrm{g}$ of protein, each reaction was performed as manufacturer's instruction in a 96 well-plate. After the reaction, HDAC activity was measured with a GENios microplate fluorometer having the Magellan software system (TECAN, Austria) with excitation at $360 \mathrm{~nm}$ and emission at $465 \mathrm{~nm}$ (Kim et al., 2005).

\section{Western blot analysis of acetylated proteins}

HeLa cells were cultured in $100 \mathrm{~mm}$ dish under a condition described above, and were treated with the compounds for $8 \mathrm{~h}$. After incubation, the cells were washed and harvested by centrifugation. The cells were then subjected to lysis with $0.5 \%$ Triton X-100 in PBS and samples were electrophoresed in $12.5 \%$ SDS-PAGE and immunoblotted onto a PVDF membrane. Membrane was incubated with antibodies against acetylated histone or tubulin (Upstate Biotechnology), and subsequently with $\alpha$-rabbit or mouse antibodies (Amersham Pharmacia Biotech Inc., Piscataway, NJ). Acetylated proteins were detected using chemiluminescence kit (Pierce, Rockford, IL). The induction fold of proteins was quantified by LAS densitometry (Fujifilm, Japan).

\section{Reverse transcriptase-Polymerase chrain reaction (RT-PCR)}

HeLa cells were treated with Psam A and SAHA for $12 \mathrm{~h}$, and total RNA was prepared. The synthesis of CDNA and a standard PCR were performed as described previously (Kim et al., 2002). Primer pairs used for RT-PCR are as the following: 5'-AGATCTGGCGTGTGGAGAAGTTCGA-3' and 5'-CTTTGACCTGGAAGAGTCTCTGCAC-3' for gelsolin, and 
5'-CCTGACCCTGAAGTACCCCA-3' and 5'-CGTCATGCAGCTCATAGCTC-3' for actin. PCR amplification conditions of each gene are as followings; $57^{\circ} \mathrm{C}$ of annealing $\mathrm{T}$ and 27 cycles for actin, and $60^{\circ} \mathrm{C}$ of annealing $\mathrm{T}$ and 30 cycles for gelsolin. The PCR products were resolved by $1 \%$ agarose gel electrophoresis. The induction fold of mRNA was quantified by LAS densitometry (Fujifilm, Japan).

\section{HPLC analysis}

The reducing agent, DTT $(10 \mathrm{mM})$, was added to Psam A $(1 \mathrm{mg} / \mathrm{ml})$ for the reduction of the compound. The mixture was incubated at $37^{\circ} \mathrm{C}$ for overnight and analyzed by HPLC using a solvent system of $40 \%$ acetonitrile. The HPLC analysis was carried out using a C18 column $(4.6 \mathrm{~mm} \Phi \times 150 \mathrm{~mm}$, Shimadzu, Japan) at a flow rate of $1 \mathrm{ml} / \mathrm{min}$. The retention time was $5 \mathrm{~min}$ for the reduced form of Psam $A$ and 14.9 min for the non-reduced form of Psam A, respectively. Amounts of Psam $A$ and reduced Psam A were measured in a time-dependent manner.

\section{Immunoprecipitation of HDAC1 from cultured cells}

HeLa cells were grown in a $100 \mathrm{~mm}$ dish and lysed with $0.1 \%$ tritonX-100 in phosphate buffer $(\mathrm{pH} \mathrm{8.0)}$. The soluble fraction collected by centrifugation was precleared with $50 \mu \mathrm{l}$ of protein A agarose beads. After the supernatant was incubated with $3 \mu \mathrm{g}$ of $\alpha$-HDAC1 antibody (Upstate biotechnology) for overnight at $4^{\circ} \mathrm{C}, 30 \mu \mathrm{l}$ of protein $\mathrm{A}$ agarose beads was added to the supernatant. The mixture was incubated for $4 \mathrm{~h}$ at $4^{\circ} \mathrm{C}$, and immune complex was collected by centrifugation, followed by washing three times with $1 \mathrm{ml}$ of washing buffer (50 mM Tris $\mathrm{pH}$ 8.0, $150 \mathrm{mM} \mathrm{NaCl}, 0.1 \% \mathrm{NP}-40,1 \mathrm{mM}$ EDTA). Using precipitated HDAC1, enzyme reaction was performed as described above. To explore the effect of oxidative status of Psam $A$ on its inhibitory activity against HDAC, DTT $(100 \mu \mathrm{M})$ or $\mathrm{H}_{2} \mathrm{O}_{2}(1 \%)$ was pretreated.

\section{Depletion of cellular reducing agent by treatment with butionine sulfoximine (BSO)}

HeLa cells were cultured in 24 well-plates, and incubated under a condition described above. After $12 \mathrm{~h}$, the cells were pre-treated with $100 \mu \mathrm{M}$ of BSO for overnight. The BSO-pretreated cells were treated with Psam A for $8 \mathrm{~h}$ and effect of BSO on inhibitory activity of Psam A against HDAC was evaluated using western blot analysis as described above.

\section{Data analysis and statistics}

Data were presented as means $\pm S D$ or as the percentage of control. Statistical comparisons between groups were performed using the Student's $t$ test. ${ }^{*} P<0.05$ was considered statistically significant.

\section{Results}

\section{Inhibitory activity of Psams against HDAC}

In order to investigate and validate the inhibitory activity of Psams against HDAC, several Psam derivatives prepared from a marine sponge (Figure 1) were subjected to in vitro HDAC enzyme assay and cell proliferation assay (Table 1). Among them, Psam $A$ and $E$ exhibited potent inhibitory activity with $\mathrm{IC}_{50}$ value of $3 \mathrm{nM}$ and $2 \mathrm{nM}$ in enzyme assay respectively, whereas the others did relatively weaker inhibitory activity than that of Psam A and E. Next, the inhibitory activity of Psams on cell proliferation was examined using HeLa cells treated with the compounds for 3 days. Most of Psams exhibited morphological change (data not shown) and growth inhibition of the cells in a dose-dependent manner. Among these derivatives, Psam A showed potent inhibitory activity $\left(\mathrm{IC}_{50} 1 \mu \mathrm{M}\right)$ than that of Psam $E$ $\left(\mathrm{IC}_{50} 3 \mu \mathrm{M}\right)$ in these cell based assays.

\section{Psam $A$ and $E$ induced the hyperacetylation of histone $\mathrm{H} 3$ in vivo}

Psammmaplins were reported to inhibit the enzyme activity of HDAC in vitro (Pina et al., 2003), yet it has not been demonstrated whether Psams induce the hyperacetylation of histones or tubulin in the cells. To explore the HDAC inhibitory activity of Psams in the cells, accumulation of both acetylated histone $\mathrm{H} 3$ and acetylated tubulin was investigated in the drugtreated cells using western blot analysis with antiacetylated $\mathrm{H} 3$ and anti-acetylated tubulin antibody, respectively. As shown in Figure $2 \mathrm{~A}$, all psammaplins induced the accumulation of highly acetyl-

Table 1. Inhibition of HDAC activity and cell proliferation by psammaplin derivatives.

\begin{tabular}{ccc}
\hline \multirow{2}{*}{ Chemicals } & \multicolumn{2}{c}{$\mathrm{IC}_{50}(\mu \mathrm{M})$} \\
& HDAC activity & Cell proliferation \\
\hline Psam A & 0.003 & 1 \\
Psam B & 0.005 & 4 \\
Psam E & 0.002 & 3 \\
Psam F & 0.05 & $>50$ \\
\hline
\end{tabular}


A<smiles>O=C(NCCSSCCNC(=O)/C(Cc1ccc(O)c(Br)c1)=N/O)/C(Cc1ccc(O)c(Br)c1)=N\O</smiles>

B<smiles>O=C(NCCSSCCNC(=O)/C(Cc1ccc(OS(=O)(=O)[O-])c(Br)c1)=N/O)/C(Cc1ccc(O)c(Br)c1)=N/O</smiles>

C

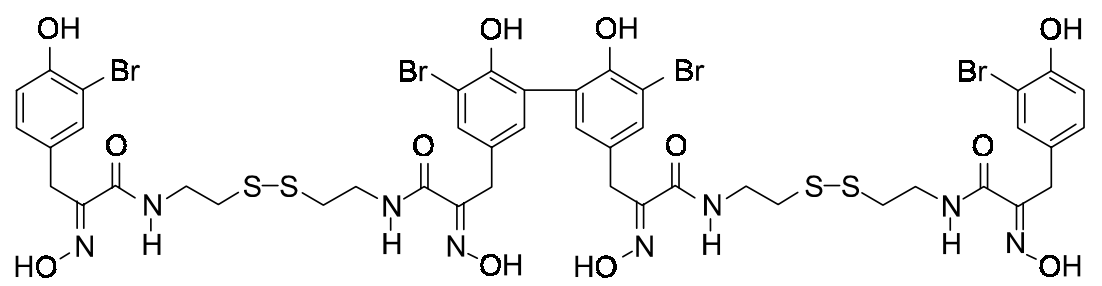

D<smiles>O=C(O[Na])/C(=C\c1cc(Br)c(O)c(-c2cc(C/C(=N\O)C(=O)NCCSSCCNC(=O)/C(Cc3ccc(O)c(Br)c3)=N/O)cc(Br)c2O)c1)O[Na]</smiles>

Figure 1. Structure of psammaplin derivatives. (A) Psam A, (B) Psam B, (C) Psam E, (D) Psam F.

A

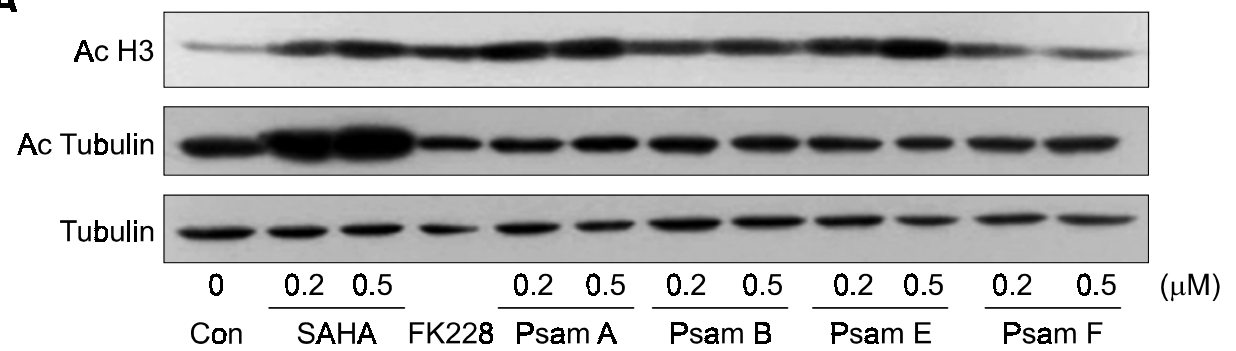

B

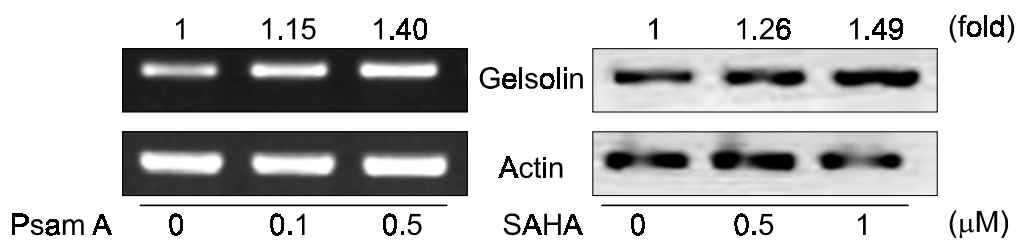

Figure 2. Effect of psammaplin derivatives on the HDAC activity in the cells. (A) Western blot analysis of the acetylated histone $\mathrm{H} 3$ or tubulin. Membrane was stained with Coomassie brilliant blue for normalization. SAHA and FK228 were treated as a positive control for verifying the inhibition of HDAC. (B) Expression of gelsolin, a HDAC target gene, by the treatment of Psam A and SAHA. Transcriptional induction fold of gelsolin was quantified by LAS densitometry (Fujifilm, Japan).

ated $\mathrm{H} 3$, as compared to control in which no drug was added, but failed to induce tubulin acetylation, indicating that psammaplins, at least in part, inhibit HDAC activity in the cells and could be specific to class I HDACs having substrate preference to histone not tubulin. Among these psammaplins, Psam
A showed the most potent activity, followed by Psam $E$, Psam B, and Psam F. Based on these results, Psam A was selected as a candidate for further detailed investigation.

Next, the cellular activity of Psam A was confirmed by examining the expression of HDAC target 
genes in the cells treated with the compound. Many reports demonstrated that the hyperacetylation of histone leads to up-regulation of tumor suppressors such as gelsolin and p21, whereas tumor activators such as vascular endothelial growth factor (VEGF) and hypoxia-induced factor- $1 \alpha(\mathrm{HIF}-1 \alpha)$ are suppressed (Van Lint et al., 1996; Saito et al., 1999; Kim et al., 2001). As shown in Figure 2B, Psam A potently induced the mRNA level of gelsolin in a dose-dependent manner and this expressional pattern was similar to that of SAHA as a positive control (i.e. Psam $A$ and SAHA induced the expression of gelsolin 1.40 and 1.49 fold, respectively). Reactivation of HDAC target genes by Psam A was well-paralleled with the hyperacetylated pattern of histone $\mathrm{H} 3$ in the compound-treated cells. These data demonstrate that Psam A potently inhibits HDAC activity in the cells.

Psam $A$ could be reduced by a reducing agent, and reduction of Psam A is important for the inhibition of the HDAC activity

Recently, several reports indicated that HDAC inhibitors having an intramolecular disulfide bond are susceptible to reduction in the cells leading to the inhibition of enzymatic activity of HDAC (Batova et al., 2002; Furumai et al., 2002; Nishino et al., 2003; Yurek-George et al., 2004). These results prompted us to investigate whether Psam A with a intramolecular disulfide bond can be reduced by a reducing agent to generate the corresponding mono-
A

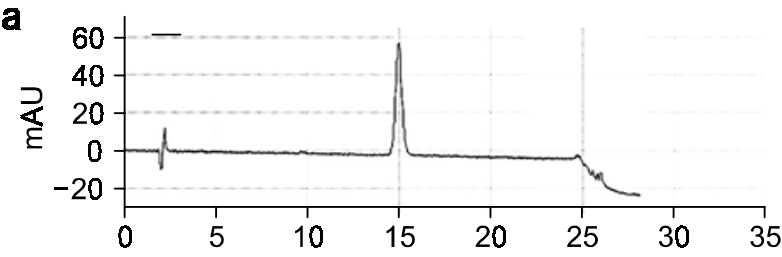

b

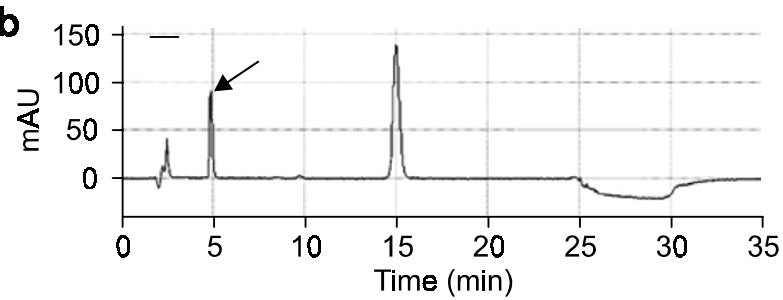

C

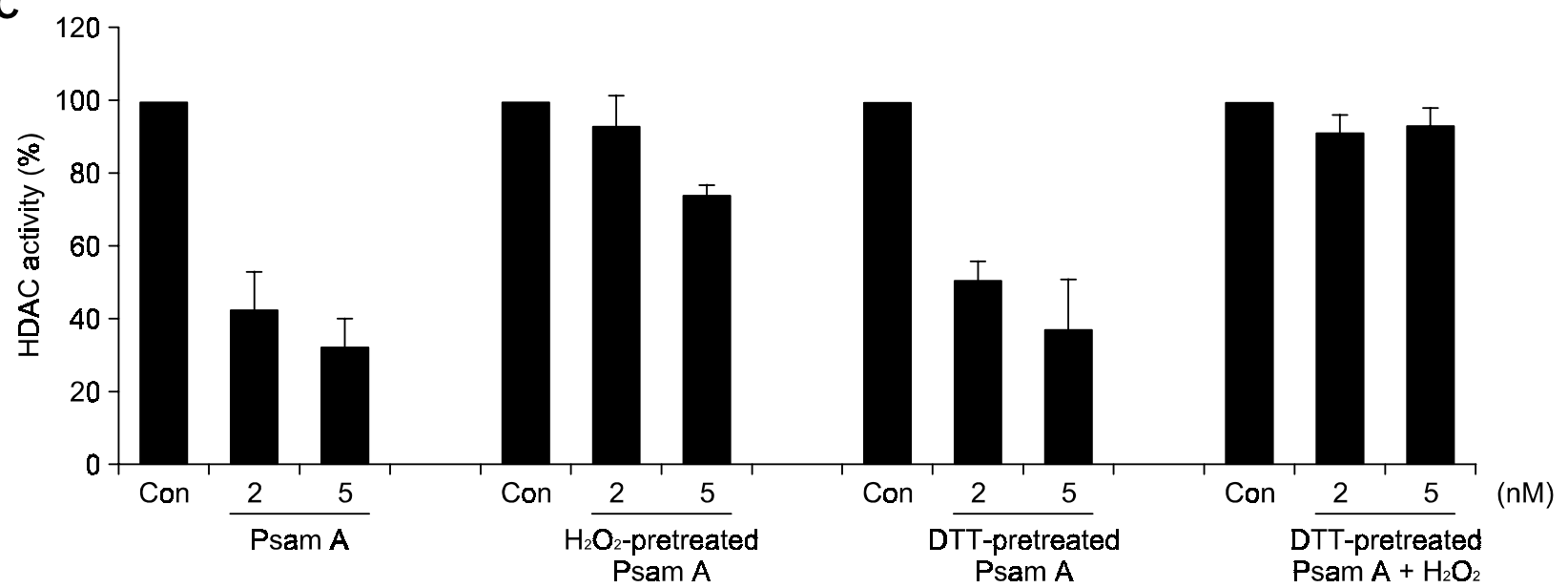

Figure 3. Effect of oxidation status of Psam A on the inhibitory activity against HDAC. (A) HPLC pattern of Psam A. a), Psam A b), DTT-treated one. Arrow represents a peak of the reduced form of Psam A, a monomeric form. (B) Amounts of Psam A and its monomer were measured in a time-course. (ם), Psam A; $(\bullet)$, reduced form of Psam A. (C) In vitro enzyme assay with immunoprecipitated HDAC1. Psam A was pretreated with or without $100 \mu \mathrm{M}$ of DTT or $1 \% \mathrm{H}_{2} \mathrm{O}_{2}$ for $2 \mathrm{~h}$. To examine whether the inhibition of HDAC activity by DTT-pretreated Psam A can be recovered by reoxidation of Psam $\mathrm{A}, 1 \% \mathrm{H}_{2} \mathrm{O}_{2}$ was added in a reaction solution.
B

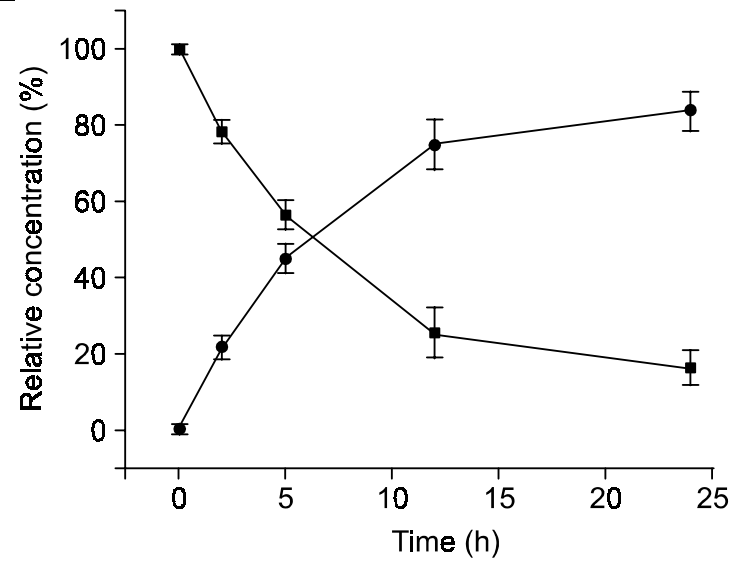


mer having thiol groups. A reducing agent, DTT (10 $\mathrm{mM})$, was added to Psam $\mathrm{A}(1 \mathrm{mg} / \mathrm{ml})$ and the mixture was incubated at $37^{\circ} \mathrm{C}$. Then, amounts of non-reduced form of Psam $A$ and reduced from of Psam A were determined in a time-dependent manner using HPLC analysis. Psam A having retention time at 15 min was decreased to $15 \%$ of input after $24 \mathrm{~h}$, whereas the reduced compound with retention time at 5 min was increased and reached a peak at $12 \mathrm{~h}$ (Figure $3 \mathrm{~A}$ and $\mathrm{B}$ ).

Next, to explore whether oxidative status of Psam $A$ affects on inhibitory activity against HDAC, in vitro enzyme assay was performed with HDAC1 isolated by immunoprecipitation method from the cultured HeLa cells. As shown in Figure 3C, Psam A potently inhibited HDAC activity at the concentration of $2 \mathrm{nM}$, and the activity was similar to DTT-pretreated Psam A. Interestingly, however, $\mathrm{H}_{2} \mathrm{O}_{2}$-pretreated Psam A remarkably lost its inhibitory activity. In addition, HDAC activity inhibited by DTT-pretreated Psam A was recovered by addition of $\mathrm{H}_{2} \mathrm{O}_{2}$. These results demonstrate that Psam $A$ can be reduced by $\mathrm{a}$ reducing agent, and this reduction is very important for HDAC inhibitory activity of Psam A.

\section{Depletion of cellular reducing activity inhibits the activation of Psam $A$, resulting in decrease of the hyperacetylated histone $\mathrm{H} 3$}

If Psam A could be reduced by the cellular reducing agent such as a glutathione, then the cells with low level of glutathione are expected to be insensitive to Psam A. To investigate this possibility, cells were pre-treated with BSO, a specific inhibitor of $\gamma$-GCS, in which the glutathione levels are markedly reduced (Shrieve et al., 1985). As shown in Figure 4A, western blot analysis using $\alpha$-acetyl $\mathrm{H} 3$ antibody showed that histone $\mathrm{H} 3$ of the cells was highly acetylated by Psam A, whereas the level of hyperacetylated histone $\mathrm{H} 3$ by Psam A was significantly decreased in BSO-pretreated cells. These results indicate that Psam $A$ is reduced by the cellular reducing agent after uptake into the cells, presumably by the same prodrug mechanism of FK228 (Figure 4B).

\section{Discussion}

Inhibition of HDAC is an emerging new strategy for developing anticancer drugs, and various compounds from natural sources and chemical synthesis have been developed as HDAC inhibitors with an aim of developing new anticancer agents (Hoshikawa et al., 1994; Saito et al., 1999; Piekarz et al., 2001). Recently, Psam A was reported to inhibit HDAC activity (Pina et al., 2003), yet the molecular details of Psam $A$ for the inhibition of HDAC remain to be uncovered. Here, we demonstrated the HDAC inhibitory activity of Psam A both molecular and cellular level and explored its mode of action as a prodrug using the cells that depleted the reducing activity. We further demonstrated that Psam $A$ is the

A

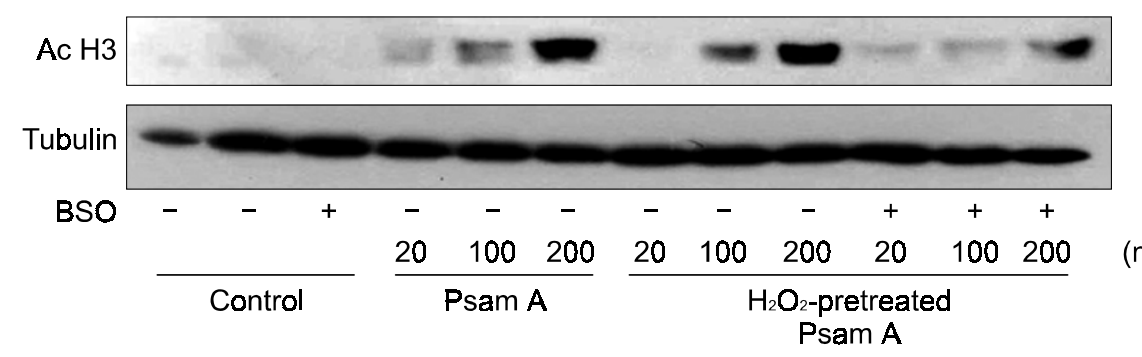

B

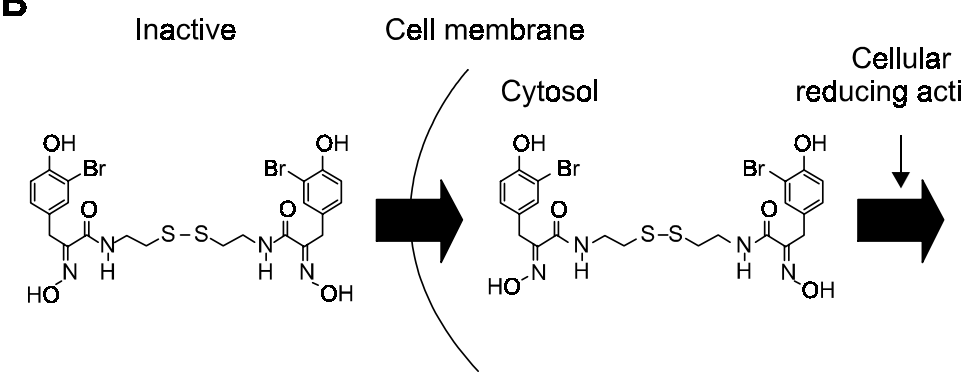

Active

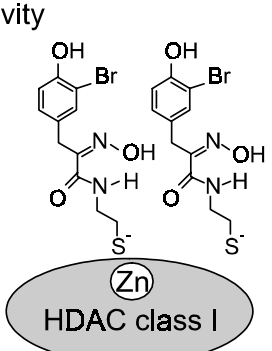

Figure 4. Effect of BSO on the HDAC inhibitory activity of Psam A. (A) HeLa cells were pre-incubated with or without $200 \mu \mathrm{M}$ of $\mathrm{BSO}$ for overnight. Psam A or $\mathrm{H}_{2} \mathrm{O}_{2}$-pretreated Psam A was treated for $6 \mathrm{~h}$, and the level of hyperacetylated histone $\mathrm{H} 3$ was analyzed by western blot analysis using $\alpha$-acetyl H3 antibody. Tubulin was used as a loading control. (B) Proposed model for the inhibition of HDAC by Psam A after uptake into the cells. 
potent HDAC inhibitor among the Psam derivatives, and proposed that the compound inhibits HDAC activity via the coordination of zinc ion in catalytic pocket of HDAC with sulfhydryl group activated by a reducing agent. These results imply that Psam $A$ could be a promising prodrug targeting HDAC.

Psam A was originally reported to inhibit several enzymatic activities such as mycothiol-S-conjugate amidase and topoisomerase II (Kim et al., 1999; Nicholas et al., 2003). More recently, it suppresses angiogenesis in vitro through the inhibition of aminopeptidase N (APN), a zinc-dependent metalloproteinase (Shim et al., 2004). As HDAC active-site structure shares common structural features of both metallopreteases and serine preteases, the proposed catalytic mechanism for deacetylation may be similar to that of zinc proteases such as matrix metalloproteases and APN (Finnin et al., 1999). In addition, the zinc protease inhibitors have a zincchelating group such as hydorxamate, sulfhydryl, carboxylate, or phosphinin group (Ondetti et al., 1977; Nishino and Powers, 1978; Kam et al., 1979). By these reasons, it is possible that sulfhydryl groups of Psam A exposed by a reducing agent can inhibit several zinc-dependent enzymes, such as mycothiol-S-conjugate amidase, topoisomerase II, APN and HDAC.

In cell based assays, Psam A selectively accumulated the hyperacetylated form of histone $\mathrm{H} 3$, but failed to induce hyperacetylation of tubulin, implying that Psam $A$ is able to discriminate between HDAC classes I and II. Eleven HDACs have been cloned from humans and classified into two groups, based on their size and number of catalytic core domains. Class $I$ is the yeast RPD3 homologous, HDAC1, 2, 3 and 8 . Class $I$ is the yeast HDA1 homologous, HDAC4, 5, 6, 7, 9, 1, and 11 (Kim et al., 2003). Interestingly, Sir2 requiring nicotinamideadenine dinucleoside (NAD) as a cofactor is identified as HDAC in yeast, and conserved in organisms that range from bacteria to human (Lander et al., 2000). Distribution and expression level of each HDAC members in tissue are diverse, and some of HDAC members have unique roles rather than basic activity of HDAC to induce the hyperacetylation of histones (Haggarty et al., 2003; Kato et al., 2004; Paroni et al., 2004). Accordingly, development of HDAC isotype-specific inhibitor needs to control specific cellular phenotypes induced by each HDAC isotype. Like other histones-selective HDAC inhibitor such as FK228, trapoxin, CHAP31 and histacin, Psam A can be a specific inhibitor of class I HDAC rather than class II HDAC having tubulin as one of major substrates.

The concept of prodrug for inhibiting HDAC activity was initiated from the study of FK228 (Furumai et al., 2002). The reduced form of FK228 by cellular reducing activity discriminates HDAC classes with high selectivity and exhibits potent activity through the strong binding to zinc ion in catalytic pocket of HDAC. In the same view point, several HDAC prodrugs have been developed recently (Nishino et al., 2003; Yurek-George et al., 2004). Those are a synthetic cyclic tetrapeptides bearing a sulfhydryl group with low cytotoxicity and good selectivity to HDAC and the other is a spiruchostatin having a sulfhydryl moiety in cyclic peptides-like structure. Because Psam A shares common structural feature with the compounds described above, it is conceivable that Psam A can be a promising natural HDAC prodrug.

Finally, our data demonstrate that the decreased glutathione level in the cells leads to significant reduction of the HDAC inhibitory activity of Psam A, indicating that cellular glutathione is important for the inhibitory activity of Psam A. Interestingly, glutathione is involved in the inactivation of anticancer drugs. For instance, conjugation of cisplatin with glutathione inhibits the conversion of mono-adducts to cross-links, thereby reducing the cytotoxic potential of the adducts in cancer cells (Kartalou and Essigmann, 2001). These drug-resistant cells with high glutathione concentration appears to be highly sensitive to Psam A, due to the higher rate of conversion of Psam $A$ to its corresponding monomer, leading that Psam $A$ is effective on tumor cells with glutathione-mediated drug-resistance. The combined use of Psam A with other anti-tumor agents that could be inactivated by glutathione may be a promising application of Psam A.

In conclusion, the present study demonstrates that Psam A could be a promising prodrug targeting HDAC and this unique property of Psam A provides a new gate for the development of HDAC inhibitor as an anti-cancer agent.

\section{Acknowledgement}

This study was supported by grants from Pine Wilt Disease Research Center of Technology Development Program funded by the Ministry of Agriculture and Forestry and from the Brain Korea 21 Project, Republic of Korea.

\section{References}

Batova A., Shao LE, Diccianni MB, Yu AL, Tanaka T, Rephaeli A, Nudelman A, Yu J. The histone deacetylase inhibitor AN-9 has selective toxicity to acute leukemia and drug-resistant primary leukemia and cancer cell lines. Blood 2002;100: 3319-24

Davie JR. Covalent modification of histones: expression from chromatin templates. Curr Opin Genet Dev 1998;8:173-8 
Dhordain P, Lin RJ, Quief S, Lantoine D, Kerckaert JP, Evans $\mathrm{RM}$, Albagli O. The LAZ3 (BCL06) oncoprotein recruits a SMRT/Msin3A/histone deacetylase containing complex to mediate transcriptional repression. Nucleic Acids Res 1998; 26:4645-51

Finnin MS, Donigian JR, Cohen A, Richon VM, Rifkind RA, Marks PA, Breslow R, Pavletich NP. Structures of a histone deacetylase homologue bound to the TSA and SAHA inhibitors. Nature 1999;401:188-93

Furumai R, Matsuyama A, Kobashi N, Lee KH, Nishiyama M, Nakajima H, Tanaka A, Komatsu Y, Nishino N, Yoshida M, Horinouchi S. FK228 (depsipeptide) as a natural prodrug that inhibits class I histone deacetylases. Cancer Res 2002;62: 4916-21

Haggarty SJ, Koeller KM, Wong JC, Grozinger CM, Schreiber $\mathrm{SL}$. Domain-selective small-molecule inhibitor of histone deacetylase 6 (HDAC6)-mediated tubulin deacetylation. Proc Natl Acad Sci 2003;100:4389-94

Hockly E, Richon VM, Woodman B, Smith DL, Zhou X, Rosa E, Sathasivam K, Ghazi-Noori S, Mahal A, Lowden PA, Steffan, JS, Marsh JL, Thompson LM, Lewis CM, Marks PA, Bates GP. Suberoylanilide hydroxamic acid, a histone deacetylase inhibitor, ameliorates motor deficits in a mouse model of Huntington's disease. Proc Natl Acad Sci USA 2003;100:2041-46

Hoshikawa Y, Kwon HJ, Yoshida M, Horinouchi S, Beppu T. Trichostatin $A$ induces morphological changes and gelsolin expression by inhibiting histone deacetylase in human carcinoma cell lines. Exp Cell Res 1994;214:189-97

Hur JM, Shim JS, Jung HJ, Kwon HJ. Cryptotanshinone but not tanshinone IIA inhibits angiogenesis in vitro. Exp Mol Med 2005;37:133-7

Jung JH, Sim CJ, Lee CO. Cytotoxic compounds from a two-sponge association. J Nat Prod 1995;58:1722-6

Kam CM, Nishino N, Powers JC. Inhibition of thermolysin and carboxypeptidase A by phosphoramidates. Biochemistry 1979;18:3032-38

Kartalou M, Essigmann JM. Mechanisms of resistance to cisplatin. Mutat Res 2001;478:23-43

Kato H, Tamamizu-Kato S. Shibasaki F. Histone deacetylase 7 associates with hypoxia-inducible factor-1 and increases transcriptional activity. J Biol Chem 2004; 279:41966-74

Kelly WK, Richon VM, O'Connor O, Curley T, MacGregorCurtelli B, Tong W, Klang M, Schwartz L, Richardson S, Rosa E, Drobnjak M, Cordon-Cordo C, Chiao JH, Rifkind R, Marks PA, Scher H. Phase I clinical trial of histone deacetylase inhibitor: suberoylanilide hydroxamic acid administered intravenously. Clin Cancer Res 2003; 9:3578-88

Kim D, Lee IS, Jung JH, Lee CO, Choi SU. Psammaplin A, a natural phenolic compound, has inhibitory effect on human topoisomerase II and is cytotoxic to cancer cells. Anticancer Res 1999;19:4085-90

Kim DH, Kim MJ, Kwon HJ. Histone deacetylase in carcinogenesis and its inhibitors as anti-cancer agents. J Biochem Mol Biol 2003;36:110-9
Kim DH, Shim JS, Kwon HJ. Coordinated transcriptional regulation of calmegin, a testis-specific molecular chaperon, by histone deacetylase and $\mathrm{CpG}$ methyltransferase. Exp Mol Med 2005;37:492-6.

Kim JH, Shim JS, Lee SK, Kim KW, Rha SY, Chung HC, Kwon HJ. Microarray-based analysis of anti-angiogenic activity of demethoxycurcumin on human umbilical vein endothelial cells: crucial involvement of the down-regulation of matrix metalloproteinase. Jpn J Cancer Res 2002;93:1378-85

Kim MS, Kwon HJ, Lee YM, Baec JH, Jang JE, Lee SW, Moon EJ, Kim HS, Lee SK, Chung HY, Kim CW, Kim GW. Histone deacetylases induce angiogenesis by negative regulation of tumor suppressor genes. Nat Med 2001;7:437-43

Lander J, Sutton A, Tafrov ST, Heller RC, Stebbin J, Pillus L, Sternglanz R. The silencing protein SIR2 and its homologs are NAD-dependent protein deacetylase. Proc Natl Acad Sci USA 2000;97:5807-11

Marks PA, Rifkind RA. Erythroleukemic differentiation. Annu Rev Biochem 1978;47:419-48

Nicholas GM, Eckman LL, Ray S, Hughes RO, Pfefferkorn JA, Barluenga S, Nicolaou KC, Bewley CA. Bromotyrosinederived natural and synthetic products as inhibitors of mycothiol-S-conjugate amidase. Bioorg Med Chem Lett 2003;12:2487-90

Nishino N, Powers JC. Design of potent reversible inhibitors for thermolysin. Peptides containing zinc coordinating ligands and their use in affinity chromatography. Biochemistry 1978;18:4340-47

Nishino N, Jose B, Okamura S, Ebisusaki S, Kato T, Sumida Y, Yoshida M. Cyclic tetrapeptides bearing a sulfhydryl group potently inhibit histone deacetylases. Org Lett 2003;5: 5079-82

Ondetti MA, Rubin B, Cushman DW. Design of specific inhibitors of angiotensin-converting enzyme: new class of orally active antihypertensive agents. Science 1977;196:441-4

Pandolfi PP. Transcription therapy for cancer. Oncogene 2001;20:3116-27

Park Y, Liu Y, Hong J, Lee CO, Cho H, Kim DK, Im KS, Jung $\mathrm{JH}$. New bromotyrosine derivatives from an association of two sponges, Jaspis wondoensis and Poecillastra wondoensis. J Nat Prod 2003;66:1495-8

Paroni G, Mizzau M, Henderson C, Del Sal G, Shineider C, Brancolini C. Caspase-dependent regulation of histone deacetylase 4 nuclear-cytoplasmic shuttling promotes apoptosis. Mol Biol Cell 2004;15:2804-18

Piekarz RL, Robey R, Sandor V, Bakke S, Wilson WH, Dahmoush L, Kingma DM, Turner ML, Altemus R, Bates SE. Inhibitor of histone deacetylation, depsipeptide (FR901228), in the treatment of peripheral and cutaneous T-cell lymphoma: a case report. Blood 2001;98:2865-8

Pina IC, Gautschi JT, Wang GY, Sanders ML, Schmitz FJ, France D, Cornell-Kennon S, Sambucetti LC, Remiszewski SW, Perez LB, Bair KW, Crews P. Psammaplins from the sponge Pseudoceratina purpurea: inhibition of both histone deacetylase and DNA methyltransferase. J Org Chem 2003;68:3866-73 
Richon VM, Webb Y, Merger R, Sheppard T, Jursic B, Ngo L, Civoli F, Breslow R, Rifkind RA, Marks PA. Second generation hybrid polar compounds are potent inducers of transformed cell differentiation. Proc Natl Acad Sci USA 1996;93:5705-8

Saito A, Yanashita T, Mariki Y, Nosaka Y, Tsuchiya K, Ando T. A synthetic inhibitor of histone deaceylase, MS-27-275, with marked in vivo antitumor activity against human tumor. Proc Natl Acad Sci USA 1999; 96:4592-97

Shim JS, Lee HS, Shin J, and Kwon HJ. Psammaplin A, a marine natural product, inhibits aminopeptidase $\mathrm{N}$ and suppresses angiogenesis in vitro. Cancer Lett 2004; 203:63-9

Shrieve DC, Denekamp J, Minchinton Al. Effects of glutathione depletion by buthionine sulfoximine on radiosensitization by oxygen and misonidazole in vitro. Radiat Res 1985;102:28394
Van Lint C, Emiliani S, Verdin E. The expression of a small fraction of cellular gene is changed in response to histone hyperacetylation. Gene Expr 1996;5:245-54

Vanhaecke T, Papeleu P, Elaut G, Rogiers V. Trichostatin A-like hydroxamate histone deacetylase inhibitors as therapeutic agents: toxicological point of view. Curr Med Chem 2004;11:1629-43

Xiao JJ, Byrd J, Marcucci G, Grever M, Chan KK. Identification of thiols and glutathione conjugates of depsipeptide FK228 (FR901228), a novel histone protein deacetylase inhibitor, in the blood. Rapid Commun Mass Spectrom 2003:17:757-66

Yurek-George A, Habens F, Brimmell M, Packham G, Ganesan A. Total synthesis of spiruchostatin A, a potent histone deacetylase inhibitor. J Am Chem Soc 2004;126: 1030-1 